\title{
Bearing replacements for Forth Road Bridge approach viaducts
}

Barry Colford BSC (Hons), CEng, MICE

Chief Engineer, Forth Road Bridge

Manuela Chiarello MEng, PhD, CEng, MICE

Engineer, Special Structures, Atkins Highways and Transportation, Epsom, UK

Chris R. Hendy MA (Cantab), CEng, FICE

Head of Bridge Design and Technology, Atkins Highways and

Transportation, Epsom, UK

\author{
Homayoon Pouya MSc, PhD, MICorr \\ Materials Engineer, Structural Rehabilitation, Atkins Highways and \\ Transportation, Epsom, UK \\ Jessica Sandberg BE, CEng, MICE \\ Senior Engineer, Special Structures, Atkins Highways and Transportation, \\ Epsom, UK \\ Paul Smout BEng, CEng, MIStructE \\ Engineer, Special Structures, Atkins Highways and Transportation, Epsom, \\ UK
}

The existing Forth Road Bridge spans the Firth of Forth in Scotland. The main suspension bridge, with central span of $1006 \mathrm{~m}$, has two multi-span approach viaducts leading up to the main crossing. The deck of the approach viaducts comprises a pair of longitudinal steel box girders supporting a series of transversely spanning steel girders, both acting compositely with a reinforced concrete deck. The steel girders of the approach viaducts are supported on steel roller and rocker bearings on concrete portal piers which vary in height between $11 \mathrm{~m}$ and $\mathbf{4 0} \mathrm{m}$. An initial study of the bearings identified that the rollers had locked up due to corrosion and distortion, and the concrete beneath the bearings and elsewhere on the pier tops had deteriorated due to chloride contamination. Assessment showed that structural deficiencies in the pier were exacerbated by both the concrete deterioration and change in articulation. These factors led to the decision to replace all the bearings on the viaducts. This paper outlines the design of the strengthening and modifications to the bridge to facilitate bearing replacement, together with a detailed description of the design of the temporary works needed to maintain the bridge's articulation during jacking.

\section{Introduction}

The Forth Road Bridge (Figure 1) spans the Firth of Forth and was completed in 1964. The main structure is a three-span suspension bridge. At each end of the bridge, there are two multispan approach viaducts comprising a pair of longitudinal steel box girders with cross-girders supporting a concrete deck slab as shown in Figure 2. The approach viaducts carry two carriageways, each with two lanes, and extend from the abutments to the side towers, which are shared with the main suspension bridge. The total width of the structure is $36 \mathrm{~m}$.

The box girders rest on steel roller and rocker bearings on reinforced concrete portal piers, varying between $11 \mathrm{~m}$ and $40 \mathrm{~m}$ high, founded on rock. The articulation of the two viaducts is shown in Figure 3(a) and 3(b). Locations with roller bearings allow for horizontal movement through movement of the roller while the locations with rocker bearings allow for movement through flexing of the piers.

During inspections and displacement monitoring, the existing roller bearings were found to exhibit little or no movement and varying amounts of corrosion. At the north side tower, the only roller bearing on the north viaduct, the roller was found to be nearing the limit of its movement range. Figure 4(a) shows a typical roller bearing, and Figure 4(b) shows the roller at the north side tower. Structural assessment of the rollers bearings to BS 5400-9-1:1983 (BSI, 1983) and BS EN 1337-4 (BSI, 2004a) showed that the original bearings did not meet modern geometrical limits and were significantly overstressed to the codes.

The rocker bearings were generally found to be in a better condition than the rollers, although some corrosion was present. A typical rocker bearing is seen in Figure 5. A structural assessment was also performed on the rocker bearings, which generally found that the bearings complied with the requirements set out in BS EN 1337-6:2004 (BSI, 2004b).

An inspection of the pier tops showed concrete delamination occurring at many of the pier tops with patches of spalled concrete in the regions directly below the bearings. Therefore, the pier tops were tested for carbonation depth and chloride contamination, which showed that many of the piers had high chloride contents and were at risk of further deterioration. Due to the poor concrete condition around and below the 


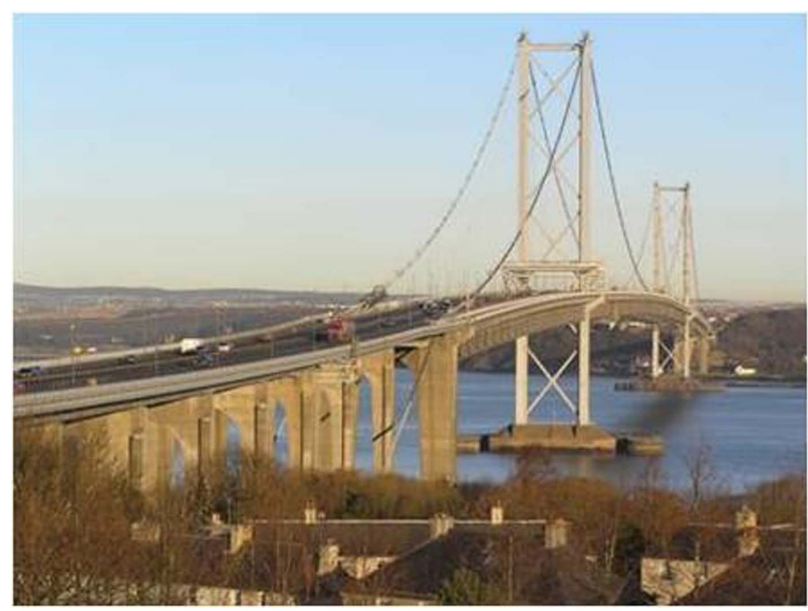

Figure 1. Forth Road Bridge, viewed from south

bearings, it was decided to replace all the bearings including the rockers (which would need to be lifted in any case for concrete repairs beneath them). To ensure the long-term adequacy of the structure, a cathodic protection system was also installed as part of the bearing replacement scheme as discussed in section 5 .

The original structure had no provision for bearing replacement so it was necessary to consider how best this was to be done through local modification and strengthening of the existing structure. The steel box and concrete substructure were therefore first assessed to determine the existing resistances of the relevant components. The remainder of this paper describes the structural assessment, the options for the new bearing types and the design and implementation of the bearing replacement solution.

\section{Bearing replacement options}

Several options were considered for the bearing type to use in the replacement of the existing roller and rocker bearings, but the overarching intention was to restore the intended articulation of the bridge.

The most feasible options for replacement of the rollers were pot bearings, sliding bearings or replacement roller bearings. A pair of pot bearings was eliminated early on because there was insufficient room to get an adequate lever arm between them to resist the torsional moments attracted by the boxes. A single pot bearing was also considered, occupying the full width of the diaphragm, but this would have required significant widening of the pier top to accommodate it. Using smaller pot bearings, partially loading the width of the diaphragms, would have been geometrically feasible but would have required strengthening to all the diaphragms; this would have been very difficult because of the extensive services passing through them. In addition, a single pot bearing could not transmit torsional reaction from the box girders, necessitating strengthening to the cross-girders at supports.

Replacing the current bearings with new roller bearings was also considered. This would involve no modifications to the diaphragm and there would be no change to the current articulation of the structure. However, the new bearings would have required a larger diameter than the original bearings in order to comply with BS EN 1337-4 (BSI, 2004a) and would not therefore fit within the available vertical space between the pier top and the box girder soffit. A higher material grade (with yield strength equal to or exceeding $690 \mathrm{MPa}$ ) was also considered to enable the diameter to be reduced, but sufficient confidence could not be obtained in the toughness of the steelwork that would be obtained.

The final solution was to adopt a sliding bearing. This minimised the changes to the original articulation, while avoiding the potential problems with brittle materials. To minimise the effect on the existing structure, the bearing was detailed with the sliding surface on the lower surface so all the eccentricity occurred on the pier and not the box girder diaphragms; the previous roller bearings shared the

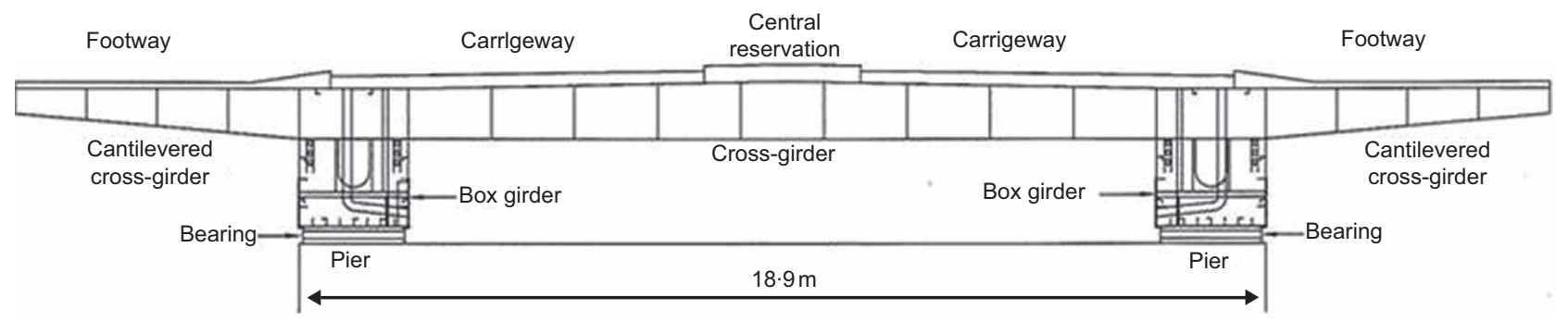

Figure 2. Cross-section through deck 


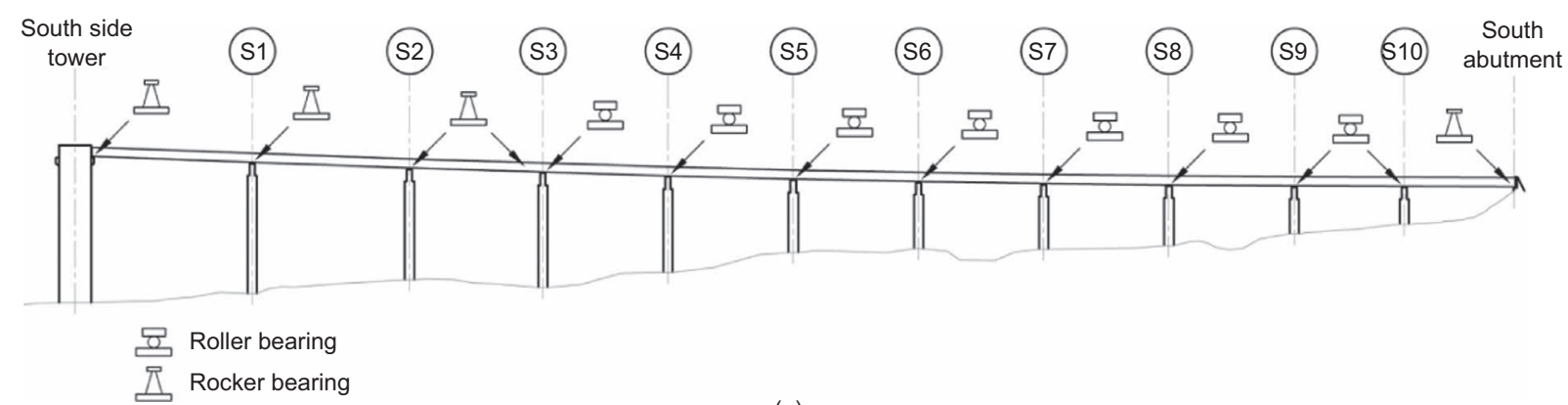

(a)

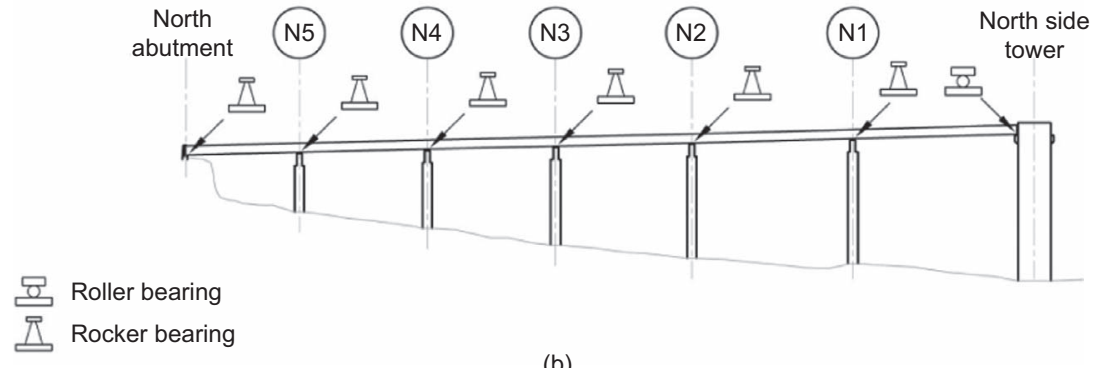

(b)

Figure 3. (a) Articulation at south viaduct; (b) articulation at north viaduct

eccentricity between the pier and box. This had a negligible effect on the overall pier load effects but was beneficial to the box girder diaphragms. It was recognised that this detail could lead to durability problems so, to prevent ingress of dirt on the sliding surface, the bearings were detailed with a protective gaiter.

For the rocker bearing, a similar process was completed for the selection and replacement rocker bearings were selected. The new bearing types are shown in Figure 6 .

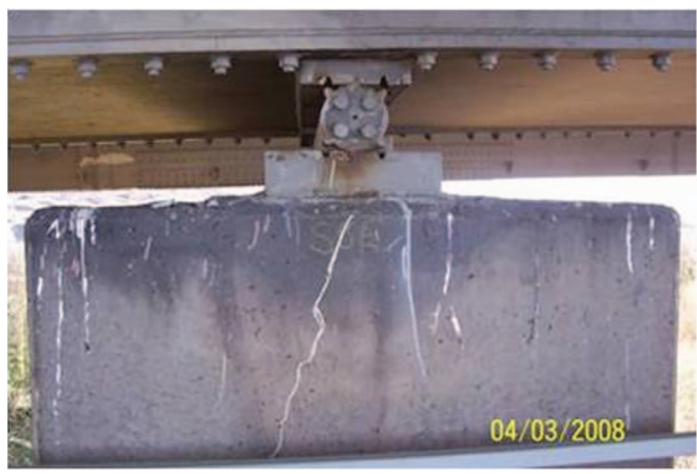

(a)

Figure 4. Roller bearings: (a) typical roller bearing; (b) roller bearing at north side tower

\section{Assessment of box girders and piers, as built}

To replace the bearings, the structure had to be modified to allow for new jacking points. Therefore, both the steel box and the concrete substructure were assessed to determine the existing resistances of the relevant components.

\subsection{Steel box girders}

A typical internal arrangement of a steel box is shown in Figure 7. The steel box girders were initially assessed using

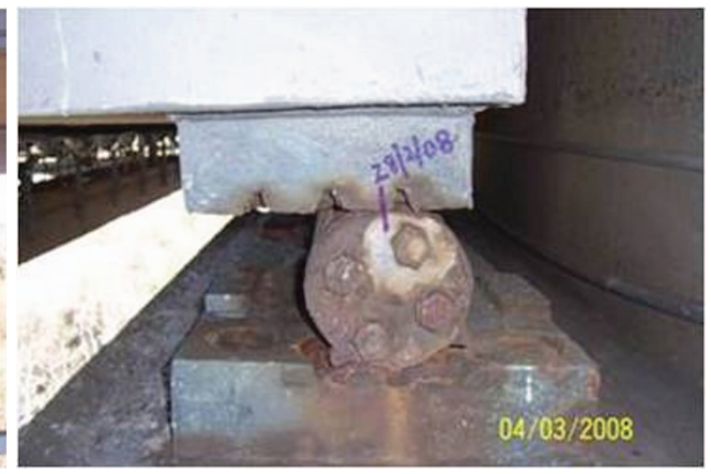

(b) 


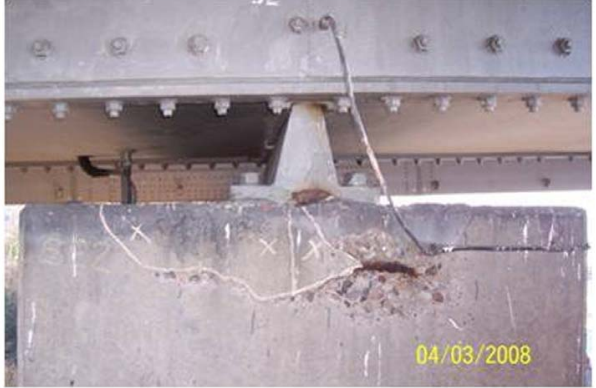

Figure 5. Typical rocker bearing

BS 5400-3 (BSI, 2000a) and BD 56/10 (Highways Agency, 2010), which found significant overstress in the existing structure. Particular areas for concern were the resistances to shear and shear-moment interaction. In addition, the shape limits for the stiffeners (to prevent torsional buckling) were not met. It was also noted that in the deteriorated condition with seized bearings, additional axial stresses were created in the steel boxes, which, while relatively small in themselves, added to the predicted overstress.

To try to avoid strengthening the boxes, Eurocode 3 was used to reassess the boxes, particularly BS EN 1993-1-5 (BSI, 2006a). This re-assessment eliminated the overstress under shear and shear-moment interaction, but the torsional buckling requirements for the stiffeners were still not met. The overall amount of strengthening required to the box girders was correspondingly reduced, but not eliminated. As the Eurocodes are based on specification of modern materials, it was important to investigate the impact of any departures from the material properties inherently assumed and take this into account during the assessment. Most relevant to this was the steel ductility, as the steel to BS 968:1962 (BSI, 1962) used in the construction of the Forth Bridge had lower ductility than modern steels. Coupon testing of steel from the boxes confirmed that the steel did, however, have adequate ductility to satisfy Eurocode requirements. 'Recommendations for assessment Eurocodes for bridges' (Hendy et al., 2011) gives further details of considerations for using Eurocodes for assessment.

\subsection{Concrete piers}

The pier tops were also assessed using the strut and tie rules in BS EN 1992-1-1 (BSI, 2004c), as strut and tie analysis is not adequately covered by BS 5400 part 4 or BD 44/95 (Highways Agency, 1995). The existing pier reinforcement consists of mild steel plain round bars. Typical piers and the strut and tie models used for their assessment are shown in Figure 8. This analysis showed that the existing reinforcement was not adequate to resist bursting loads in the pier tops, but the pier was adequate if the tensile strength of the concrete was invoked. Although this explained why there was no distress in the existing condition, it was not considered an acceptable permanent solution considering the ongoing concrete deterioration.

The piers were also assessed for global behaviour, including the longitudinal loading due to temperature expansion and contraction on the piers with rocker bearings. The adequacy of these piers was demonstrated by considering cracked behaviour in accordance with the recommendations given in BS EN 1992-1-1 clause 5.8.7 (BSI, 2004c); without considerations of cracking, the piers were stiffer, attracted too much load and their resistance was exceeded. Adequacy could also be demonstrated in this way in the condition with seized bearings.

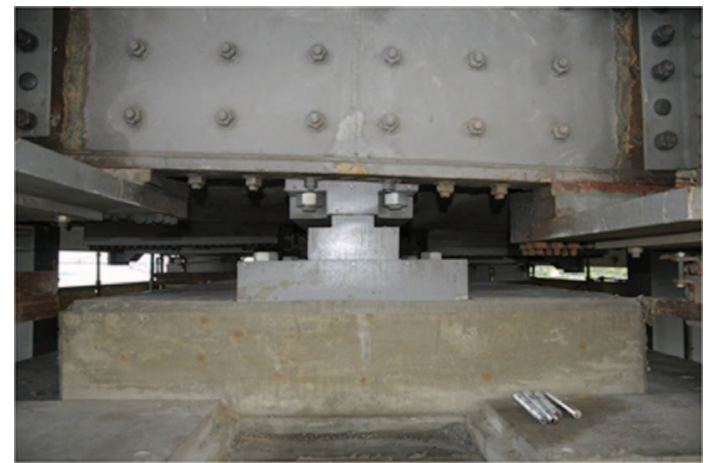

(a)

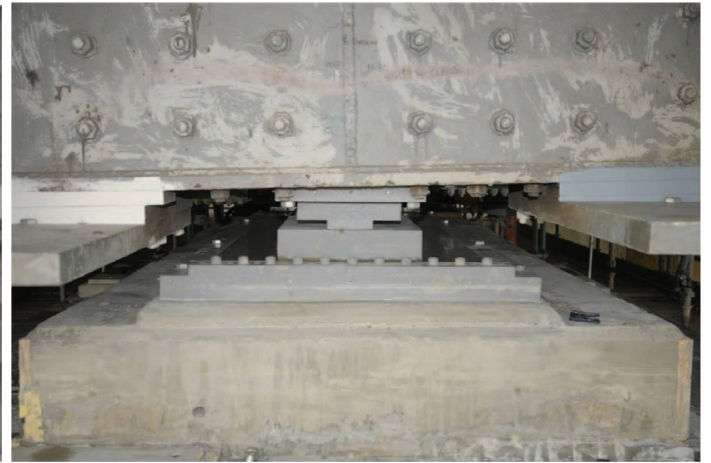

(b)

Figure 6. New bearings: (a) rockers and (b) sliders 


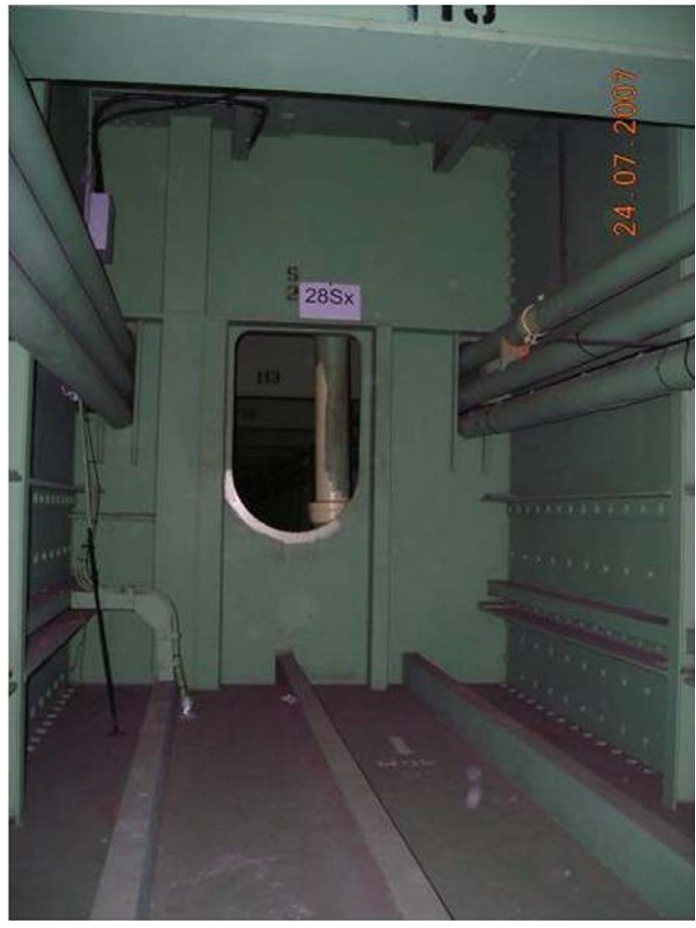

Figure 7. Typical internal view of box girder

\section{Solution for bearing replacement: corbels and steelwork}

\subsection{General requirements}

The bridge is a category A listed structure and is highly visible, so all parts of the strengthening work to facilitate bearing replacement had to be in keeping with the existing structure and were subject to approval by the two adjacent planning authorities in conjunction with Historic Scotland. However, all parties accepted that the visual considerations had to be balanced with the structural and safety considerations of the work as discussed below. A key aspect of the scheme design was that it should also facilitate future bearing replacements, should they become necessary.

\subsection{Scheme outline}

Replacement of the bearings necessitated jacking up the box girders to release the existing bearings, but there was insufficient space for jacking at the pier tops and no suitable location on the box girders to apply the jacking forces. The solution chosen was to add corbels to the tops of the piers to provide adequate space for the jacking equipment and to add jacking stiffeners to the box webs. These are discussed in sections 4.3 and 4.4 respectively, and were selected because they provided a permanent solution for bearing replacement while also being more economic than options involving temporary propping. In addition, the design needed to maintain the articulation of the bridge throughout the replacement process, which meant providing longitudinal fixity at rocker bearings and a controlled release of unintended force at roller bearing positions. This is discussed in section 4.5.

A key feature of the jacking scheme was the use of four jacking points at each box girder support. This was necessary for a number of reasons including lack of available room at the pier top in line with the diaphragms (because of the limited available clearance to the permanent moving maintenance gantry) and the presence of cross-girders in line with the diaphragms limiting the available height for jacking stiffener addition in line with existing diaphragms. This is discussed in section 4.6.

A typical sequence for a bearing replacement is as follows

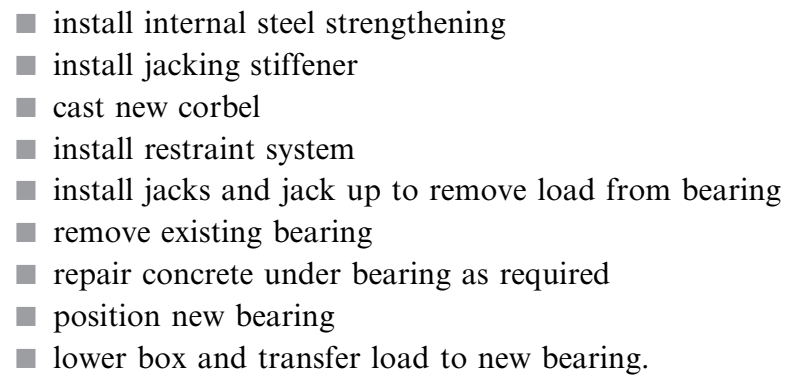

Heavy equipment was generally winched to the pier tops from the existing deck cross-girders.

As the construction sequence was complex and the designers' risk assessment identified non-compliance with it as a significant risk, a virtual reality model was used to highlight the different construction stages in the project in order to minimise the risks of errors being made in the construction sequence. This followed the successful use of a similar model on a previous bearing replacement project (Smith and Hendy, 2008). The main features of the bearing replacement scheme are shown in Figure 9, extracted from the virtual reality model.

\subsection{Concrete corbels}

The concrete corbels were designed to be permanent extensions to the existing pier and served two purposes: to provide adequate space to position jacks; and to facilitate installation of permanent bursting reinforcement in the pier tops.

The corbels had to carry the load from the temporary jacks to allow the permanent bearings to be replaced while also allowing the pier top concrete to be broken out and recast when needed to rectify the deterioration. For this reason, the corbels were cast $300 \mathrm{~mm}$ below the top of pier level so that pier top breakout would not undermine the new corbel reinforcement. Space and aesthetics were the major constraints 

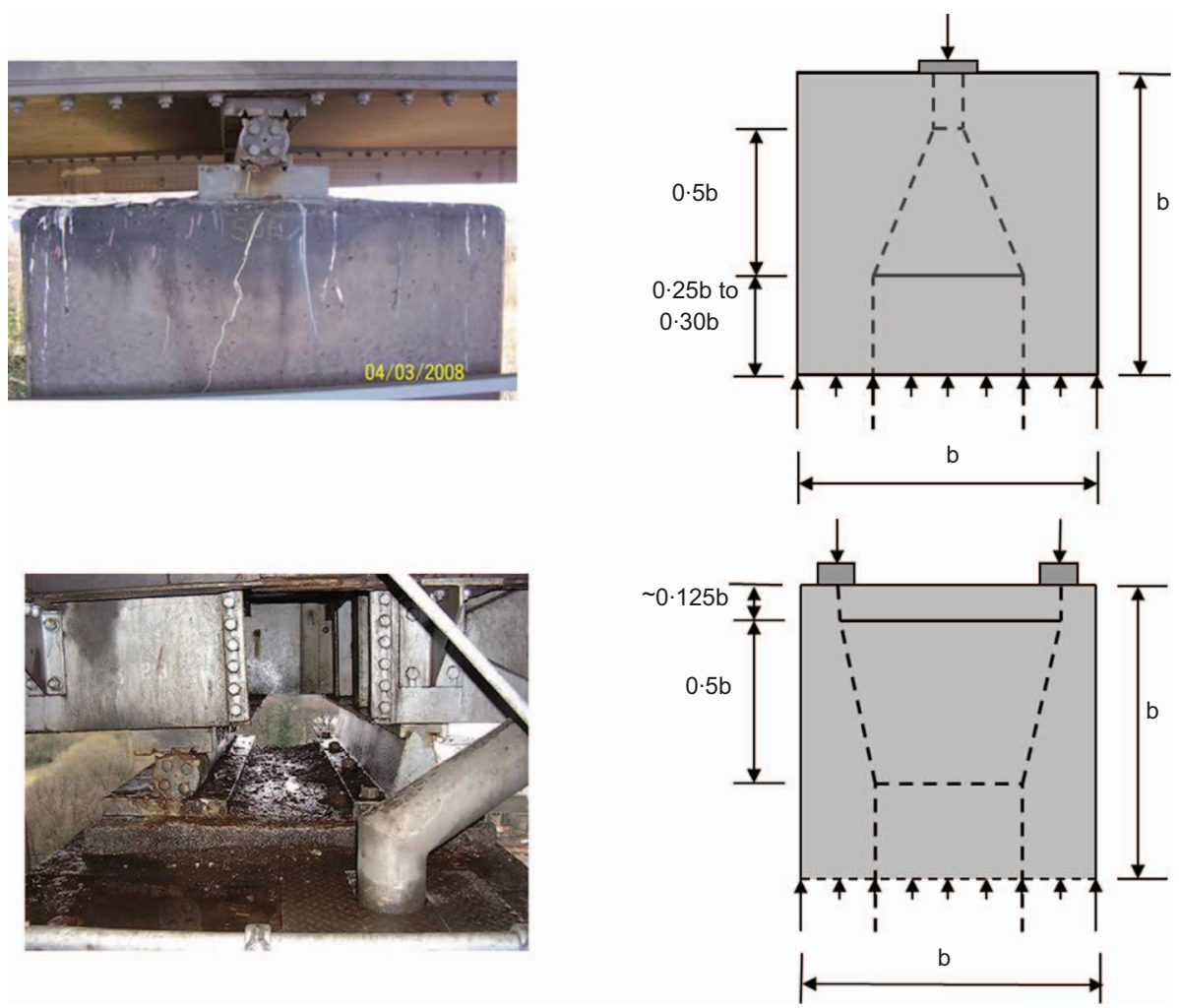

Figure 8. Analysis of typical piers with strut and tie analysis:

(a) roller bearing; (b) roller bearing idealisation; (c) twin bearing; (d) twin bearing idealisation

in the design of the corbels. Their width in the longitudinal direction of the bridge was dictated by the need to tie in with a pre-existing concrete feature extending up the sides of the piers, as shown in Figure 10. Their width perpendicular to the bridge span on its outer face was limited by the clearance to the existing maintenance gantry.

A typical final installed corbel is shown in Figure 11.

The corbels were designed using strut and tie models of the generic form shown in Figure 12, which necessitated the anchoring of new reinforcement into the existing pier. This required holes to be drilled into the existing structure and new reinforcement resin grouted in. Figure 12 shows typical reinforcement resin anchored through the thickness of the pier before drilling for the addition of the pier transverse reinforcement. This transverse strengthening reinforcement extended up to $5 \mathrm{~m}$ into the pier because, in addition to functioning as part of the corbel, it was also designed to replace the existing transverse top mat of reinforcement while this was exposed during the repair work of the concrete at the top of the pier. The corbel reinforcement also provided bursting reinforcement for the permanent condition, which had been found to be deficient by the assessment.

It was accepted that some bars would inevitably be damaged during coring operations, so a coring protocol was developed in advance of construction to set out the numbers and locations of bars that could be damaged without remedial work being required. This allowed site staff to make the decision on what to do when an existing bar was hit and to update their strategy for the remaining cores.

The main reinforcement in the corbel needed to pass through the full width of the pier and be fully anchored at each end. Obviously the bars could not be detailed with a bend at both ends as they could not then be threaded through the core hole. Corbel width was very limited and, at some locations, there was inadequate room to couple on to the end of the straight bar with a bent bar to form the bar anchorage. In these locations, the bars were fitted with end plates by means of a threaded connector. On each side of a pier at these locations, main bars were alternately anchored by reinforcement bend and by end plate, as shown in Figure 13. This detail suited the 
Bridge Engineering

Volume 167 Issue BE3
Bearing replacements for Forth

Road Bridge approach viaducts

Colford, Chiarello, Hendy et al.

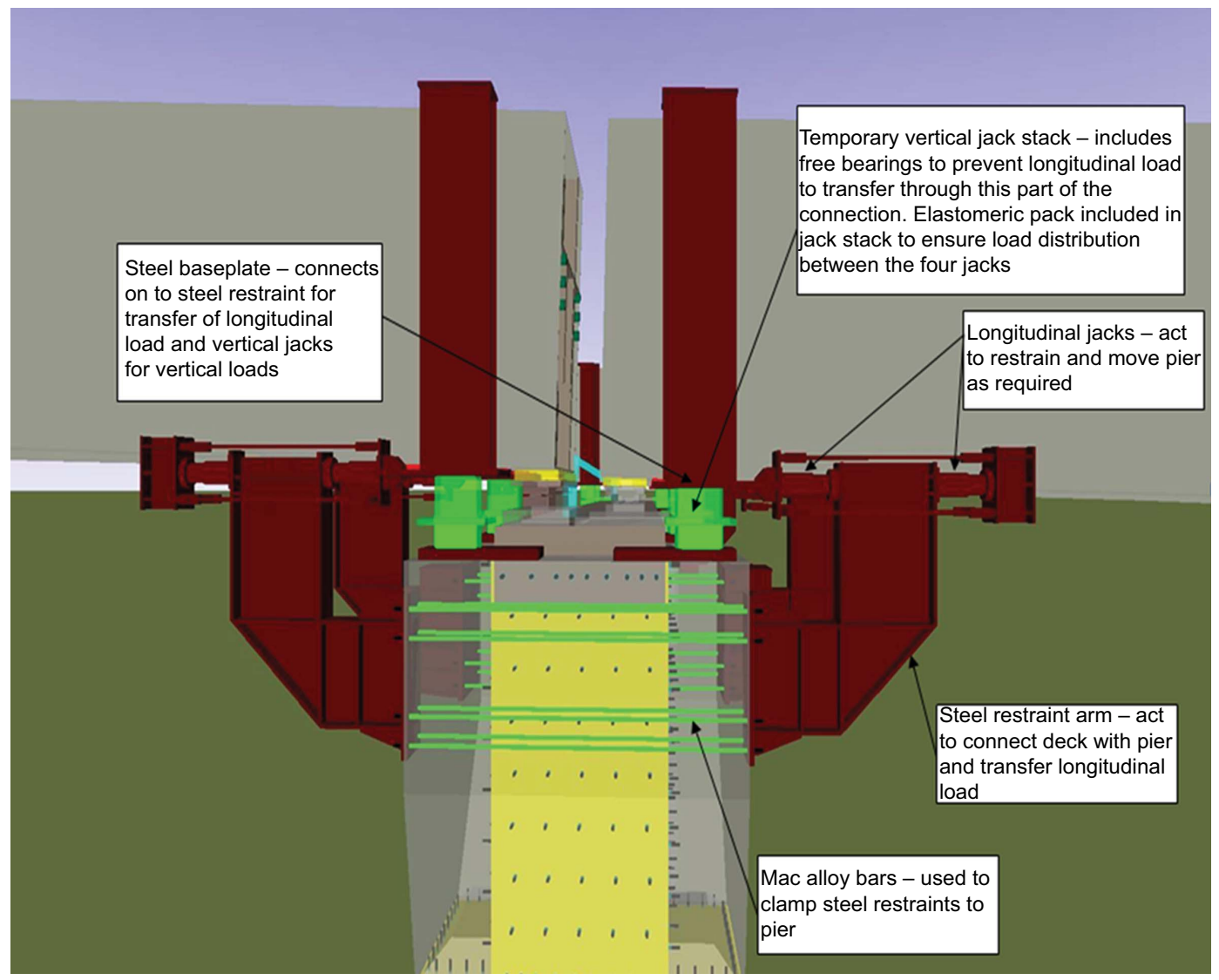

Figure 9. Scheme features in virtual reality model

corbel strut and tie arrangement well but could only be used in areas of no or low fatigue due to the relatively poor fatigue performance of threaded coupling devices. Some limited fatigue testing was carried out on the T-head connection to ensure that it was equivalent in performance to the $\mathrm{S}-\mathrm{N}$ curve provided in BS EN 1992-1-1 (BSI, 2004c) for 'splicing devices', which was adequate for the fatigue stresses in this region.

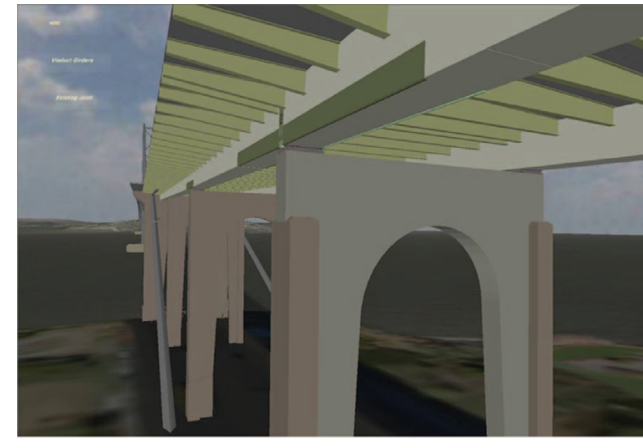

(a)

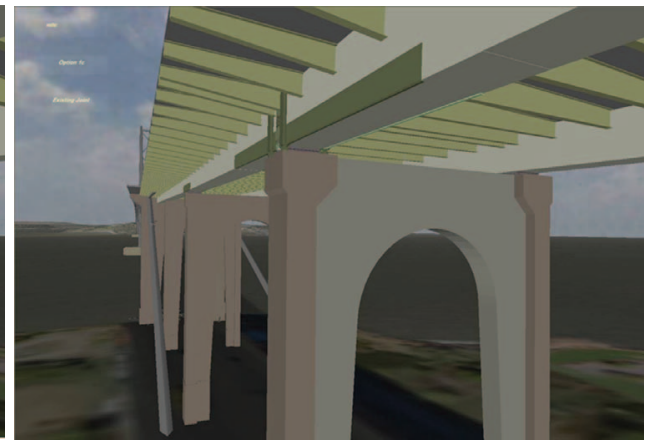

(b)

Figure 10. Corbel addition to tie in with existing vertical pier feature: (a) before corbel additon; (b) after corbel addition 
Bridge Engineering

Volume 167 Issue BE3
Bearing replacements for Forth

Road Bridge approach viaducts

Colford, Chiarello, Hendy et al.
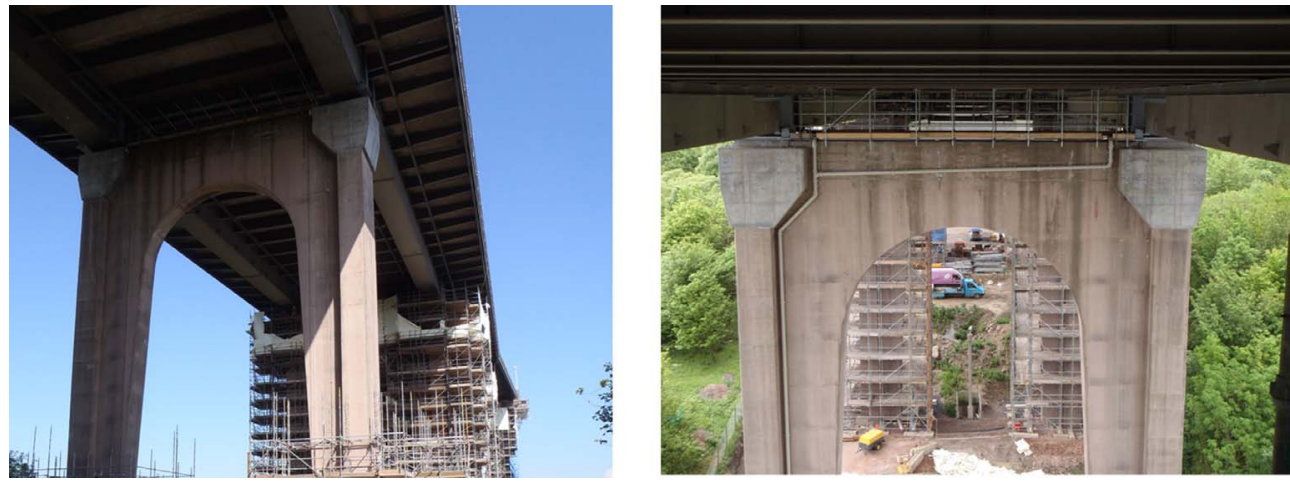

Figure 11. Corbel addition on site

Because of the limited head room available to facilitate vibration and compaction of the concrete, self-compacting concreting was used to construct the corbels. Ahead of construction on site, a full scale mock-up corbel was constructed to trial the proposed self-compacting concrete and to check the bond at the interface with the existing pier. This highlighted some improvements to make to surface preparation, concrete mix and initial reinforcement layout, proving that the trial was a valuable undertaking.

\subsection{Steelwork}

To minimise the hazards associated with working in the confined space environment of the steel box and to avoid damage to the extensive existing services within the box, the main components of the strengthening needed for jacking were added to the outside of the steel box girder. This comprised single-sided box section jacking stiffeners (Figure 14) similar to those developed for the strengthening of Irwell Valley Bridge (Smith and Hendy, 2008) where their design methodology is described. A number of alternative arrangements were

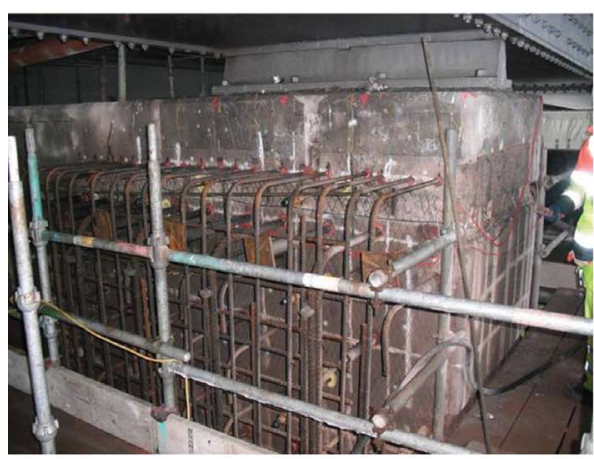

(a)

Figure 12. (a) Typical corbel reinforcement and (b) corresponding strut and tie model provided for these box stiffeners to give flexibility in the location of the bolted attachments to the webs. Weathering steel was used for the jacking stiffener because of the lack of access to its internal surfaces. The only internal steelwork strengthening was additional bolted longitudinal stiffeners (to strengthen the webs before drilling the holes for the jacking stiffeners) and some additional plating to existing longitudinal stiffener angles (required to prevent torsional buckling). The new longitudinal stiffeners were rolled steel angles connected to the webs through one leg. Welding was not used for the connections because of concerns over the ability to weld to the existing steel without laminating it and because of the confined space environment inside the boxes.

The steelwork design was carried out in accordance with Eurocodes, specifically

BS EN 1993-2 (Steel bridges) (BSI, 2006b)

- BS EN 1993-1-5 (Plated structural elements) (BSI, 2006a)

BS EN 1993-1-8 (Design of joints) (BSI, 2005).

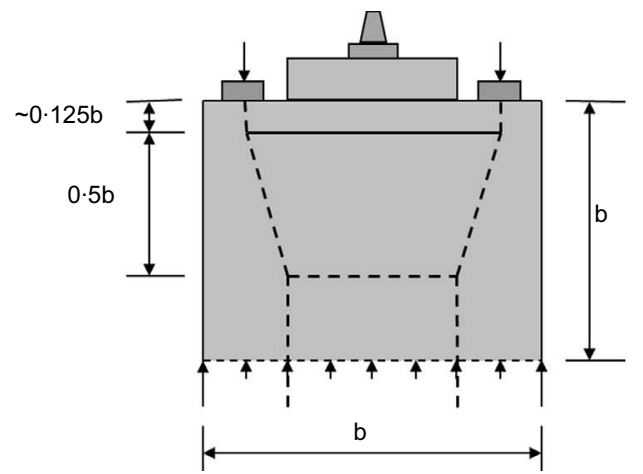

(b) 
Bearing replacements for Forth

Road Bridge approach viaducts

Colford, Chiarello, Hendy et al.

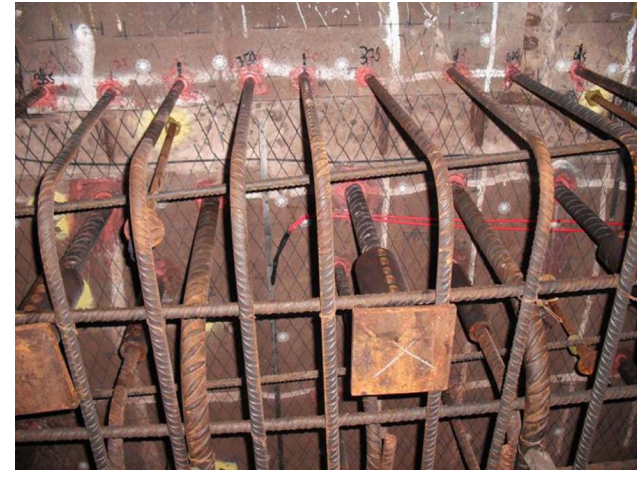

Figure 13. Bars with T-head connection

At the end supports, the services were found not to be ducted where they passed through access holes in the box webs and diaphragms. The risks of carrying out work adjacent to these services, comprising fibreoptic cables, was considered too great so it was decided to move the new longitudinal stiffeners to the external faces of the webs at these locations. Also, the strengthening of the existing longitudinal web stiffeners on the internal web faces was replaced by additional new longitudinal stiffeners on the external web faces. Moving the stiffeners to the outside of the box in this way increased the steelwork quantities but improved buildability as the plates did not need to be brought into the box. External stiffeners were therefore considered elsewhere but proved to be less convenient

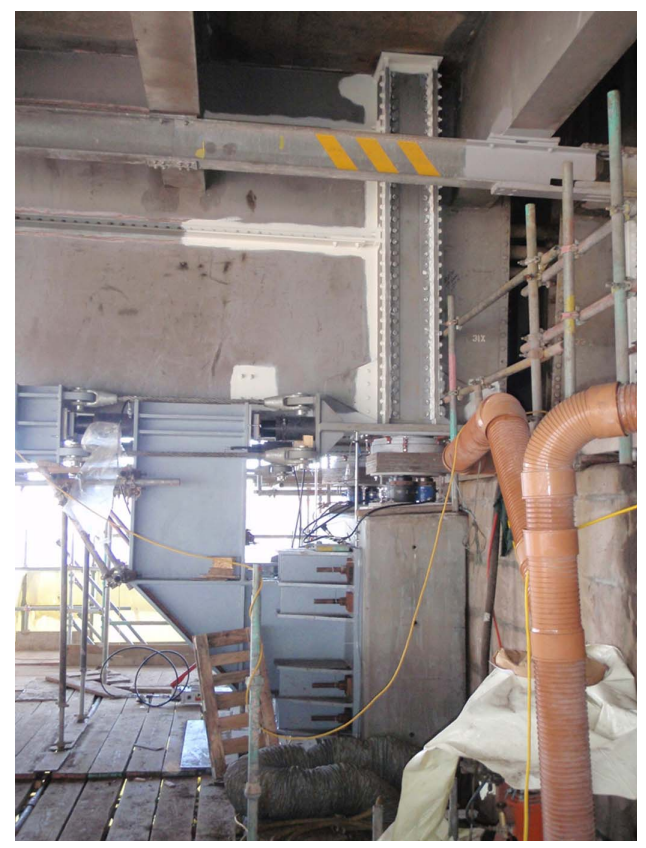

Figure 14. Typical box jacking stiffeners because of the difficulties of getting continuity across the jacking stiffeners at intermediate piers, as was needed in the design.

\subsection{Restraint systems}

The articulation of the bridge needed to be maintained during bearing replacement. As the longitudinal forces at fixed bearings were too large to take in shear on the jacks, separate temporary restraint systems were provided to connect the bridge superstructure to the substructure during the bearing replacement process. The form of the restraints varied according to the location, but at the intermediate piers longitudinal restraint was provided by four steel brackets positioned in pairs each side of a box, one pair either side of the pier, anchored to the pier using Mac alloy bars passing through holes in the pier. Transverse restraint (to the smaller forces from wind and skidding loads) was provided by the jacking stacks themselves. This required the use of a guided temporary bearing on one of the jack stacks at a box support location to resist the shear, with free bearings at the other jack locations. Similar systems were designed for the abutments and side towers, but these are not described here.

The purpose of the restraint system at rocker bearing locations was to fix the bridge piers to the superstructure throughout the bearing replacement while the fixity of the permanent bearings was temporarily released. The steel brackets at intermediate piers were of the form shown in Figure 15 with a horizontal jack connecting the top of each restraint to the adjacent jacking stiffener base plate. The jacks allowed the differential horizontal movement between the superstructure and substructure to be controlled under the small deflections occurring in the steelwork itself. The system in Figure 15 was the arrangement for pier $\mathrm{S} 3$ where two simply supported box ends landed on a shared pier and hence an additional set of jacks and tie bars were provided so the restraint system could both

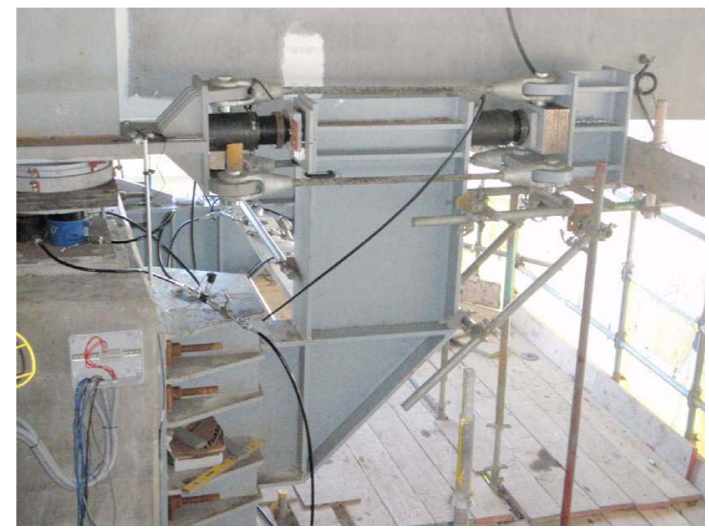

Figure 15. Typical temporary longitudinal restraint 
push and pull. At continuous box locations these additional features were unnecessary as the restraints only needed to carry forces in one direction. The horizontal restraint jacks were engaged before lifting the superstructure and remained engaged during the bearing replacement until the girders were lowered down onto the new bearings.

The restraint systems at roller bearing locations were similar but were provided only to control the release of force locked into the roller bearings. It was known such forces existed from earlier pier monitoring. Lifting of the superstructure under these conditions could have caused a sudden release of horizontal force and a springing back of the pier in a potentially dangerous sudden movement. The provision of jacks allowed this force and movement to be released in a controlled and safe manner.

In all cases, generous allowance for eccentricities was made in the design of the steelwork because aligning the temporary restraint brackets, whose position was fixed by the locations of the core holes for the Mac alloy bars, with the jacking stiffener base plate stiffening had significant tolerance.

As a result of this provision of temporary fixity, no limit was set on the number of piers that could be jacked up at any one time.

\subsection{Design of jacking system}

The jacking scheme utilised two jacking points per bearing at each abutment and side tower and four jacking points at other pier locations. The jacking system at each jacking point comprised three jacks supporting either a transversely guided or free pot bearing; the initial concept utilised only one large jack at each jacking point but this was modified once on site to suit the equipment available (Figure 16(a)). This ensured that the relatively small transverse forces from the deck (due to wind and skidding) were taken through the guided bearings and then through the jacks to the piers. Longitudinally, the bearing transmitted no loading to the jacks (other than from friction at the roller bearing piers). Longitudinal forces at rocker piers were carried by the temporary longitudinal fixities described in section 4.5 because the shear forces were too large to be carried by the jacks and additionally the uneven bearing pressure resulting on the jacks from the longitudinal force would have been too great for the concrete.

At locations with four jacking points, the load at each jacking point after lock-off was potentially very uneven under live loading due to the torsion attracted to the boxes and the tendency to uplift on the 'back span' jacks where only one span was loaded. To prevent uplift at a jack position and to distribute the loads between them more evenly, thus minimising the strength requirements for jacking components and box strengthening, the stiffness of each jacking system was reduced by incorporating an elastomeric pad between the jack and temporary bearing within a further bespoke bearing capable of transmitting transverse shear. The assembly formed by these three components was referred to as the 'jacking stack' and is shown in Figure 16(b) undergoing a load test.

The determination of the required stiffness for each jacking stack was carried out by linear finite element analysis of the entire south viaduct. Box girders, transverse beams, diaphragms, internal stiffeners and concrete slab were all modelled with thick shell elements, while the jacking stiffeners were added as beam elements. Figure 17 shows the distribution of forces between the four jacking points as a function of elastomeric pad stiffness at pier S4. The jacking sequence included the jacks being hydraulically linked for dead loads and subsequently locked-off for live loads. A maximum stiffness of $10^{7} \mathrm{kN} / \mathrm{m}$ was needed to prevent uplift at a jack. The upper line shows the total force in all the jacks. It can be seen that below a stiffness of $10^{5} \mathrm{kN} / \mathrm{m}$, the forces in the jacks were very even but the flexibility is such that load was shed to adjacent piers, which was undesirable. The vertical flexibility under live load would also have compromised the ability to grout below the new bearings. Full three-dimensional modelling was essential to model the redistribution of torque also caused by the softer bearing support; this slightly increased the stress resultants in the support cross-girders.

The final design stiffness of the jack stack was tuned to a value between $10^{6} \mathrm{kN} / \mathrm{m}$ and $10^{7} \mathrm{kN} / \mathrm{m}$ so that uplift could not occur under any load combination and load was shared economically between jacks, but the vertical displacement under load would not be so great as to disrupt grouting beneath the permanent bearings. That latter was set at $0.2 \mathrm{~mm}$ and this proved to cause no problem during grouting.

\section{Cathodic protection}

The inspection and concrete test data indicated that the cause of concrete deterioration was chloride-induced corrosion, possibly from the initial use of de-icing salts in the first 20 years of the bridge's life. The chloride ion content at the majority of pier tops and both abutments was in excess of the threshold value of $0 \cdot 3 \%$ by mass of cement and the 'diffusion' calculations suggest that the critical level at the depth of reinforcement would be reached in the next 5-8 years. Action was therefore required to arrest continued deterioration. Various repair options were considered but the application of cathodic protection to the piers, side towers and abutments, together with minimal concrete repairs solely to the delaminated areas, was evaluated to be the most cost-efficient solution for the substructure.

An impressed current cathodic protection system was selected with design undertaken in compliance with the recommendations 


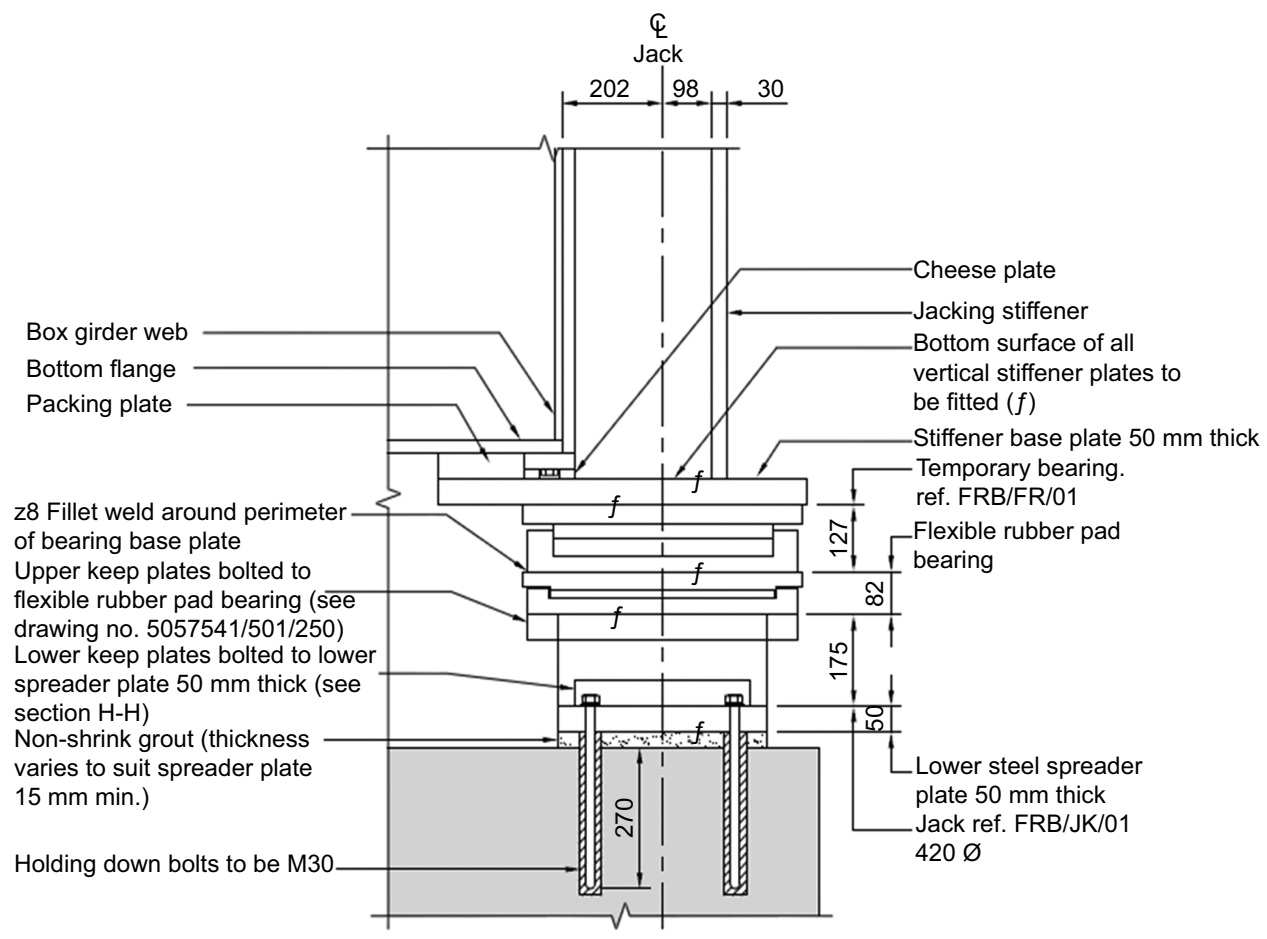

(a)

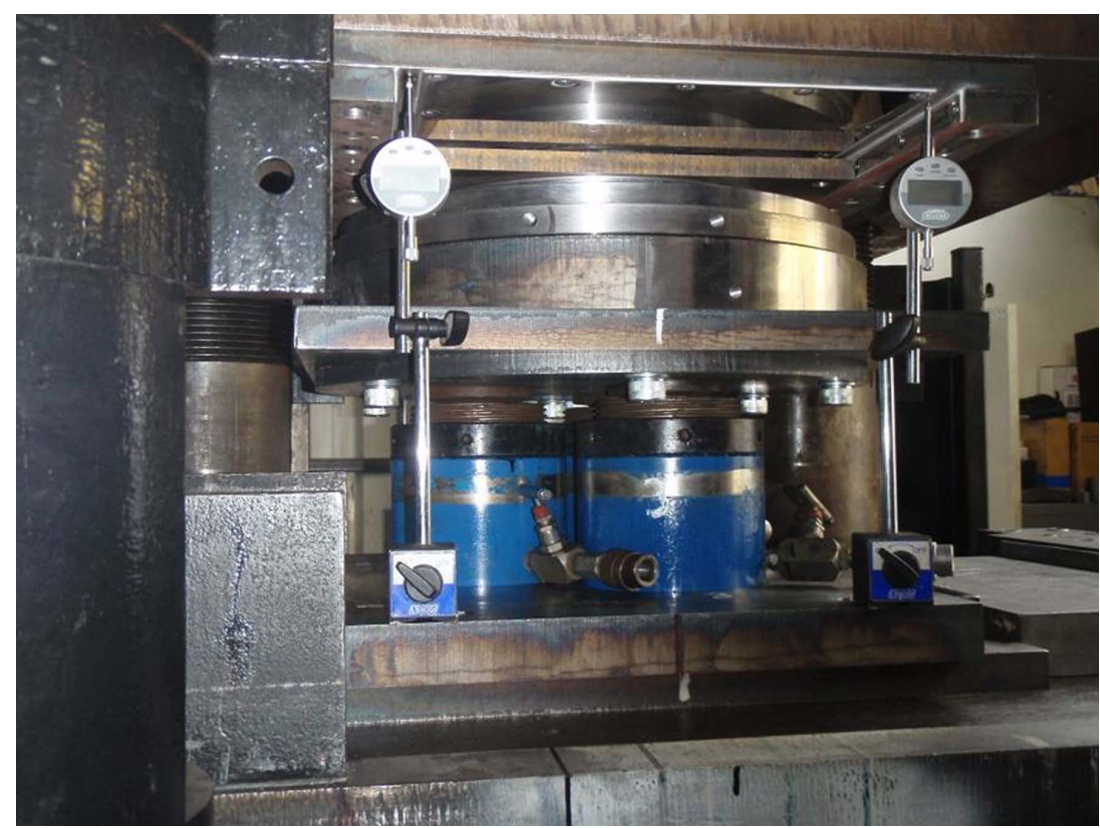

(b)

Figure 16. Jacking stack: (a) concept with single jack (dimensions in $\mathrm{mm}$ ); (b) final three-jack system undergoing load test

of BS EN 12696:2000 (BSI, 2000b), the National Association of Concrete Engineers (NACE, 2000) and the Concrete Society report (Concrete Society, 1989). Three types of anode systems were used in the design: titanium meshbased anode to be installed at the interface of concrete substrate and new corbels; titanium ribbon-based anodes to 


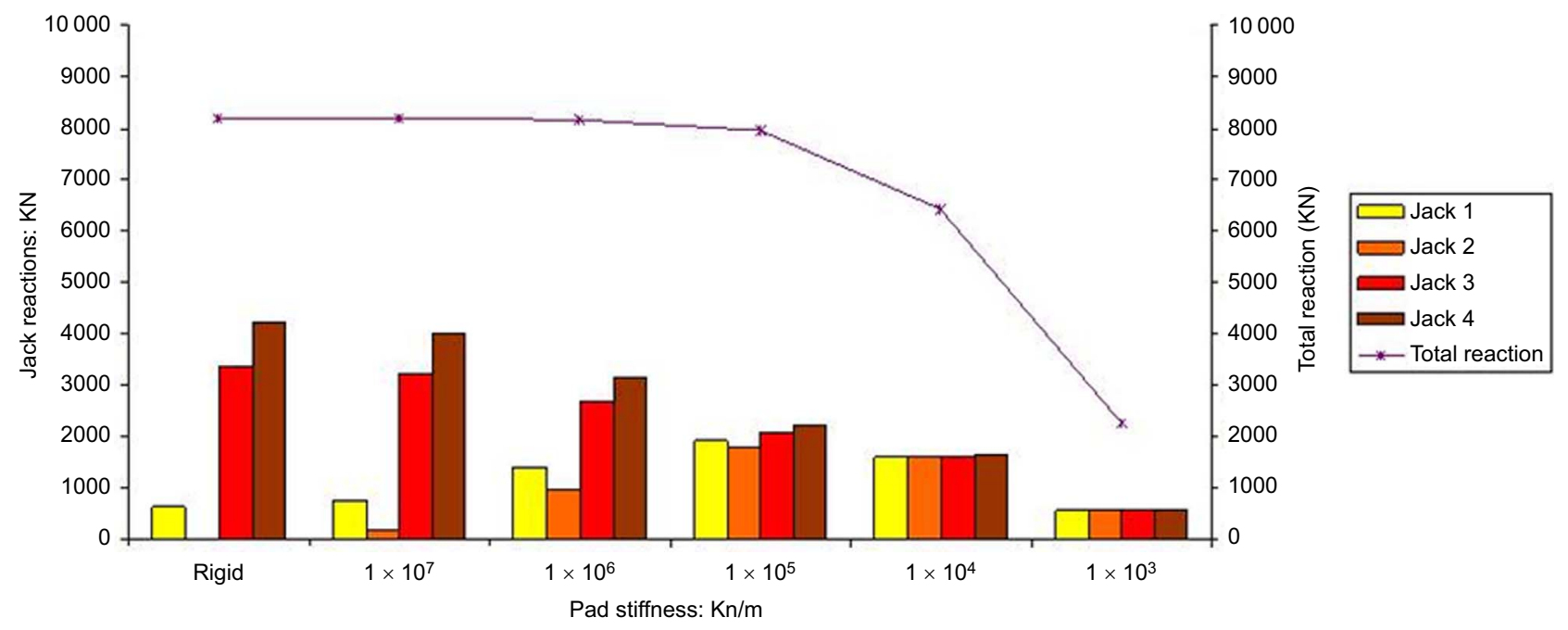

Figure 17. Results of sensitivity analysis on elastomeric pad stiffness

be installed within slots cut into the concrete cover; and titanium ribbon-based discrete anodes designed to be installed within holes drilled into the structure. Reference electrodes for monitoring the performance of each anode zone were also included.

The area covered by each anode zone was designed to be independently powered by an integrated power supply and data acquisition unit, which will provide the facility for controlling the voltage and current to each zone; and monitor/control the performance of the cathodic protection system. All units are installed within two networks (one for each approach viaduct). On each network all units were detailed to be operated from a single main control unit either locally on site or remotely by means of a modem connection.

\section{Conclusion}

The replacement of the bearings on the Forth Road Bridge is a very significant undertaking because of the lack of provision for this eventuality in the initial bridge design. The solution developed, involving modification of the structure to provide permanent jacking points on superstructure and substructure, now makes any future bearing replacement or refurbishment a much simpler, quicker and cheaper operation. The permanent modification to the structure, by the addition of corbels to the piers and external stiffening to the box girders, was carried out sympathetically to the original design and under the scrutiny of Historic Scotland.

A number of measures were taken to minimise the cost of the modification works and could be considered for future bearing replacement schemes. These included the use of Eurocodes for the assessment of the existing structure and design of the new works, the use of external stiffening to improve buildability and the use of elastomeric pads incorporated in the jacking system to give a better distribution of jack loads after lock-off and hence reduced demand on the new stiffening and concrete corbels.

\section{REFERENCES}

BSI (British Standards Institute) (1962) BS 968, High tensile (fusion welding quality) structural steel for bridges or general building purposes. BSI, London, UK.

BSI (1983) BS 5400-9-1:1983. Steel, concrete and composite bridges. Bridge bearings. Code of practice for design of bridge bearings. BSI, London, UK.

BSI (2000a) BS 5400-3:2000. Steel, concrete and composite bridges. Code of practice for design of steel bridges. BSI, London, UK.

BSI (2000b) BS EN 12696:2000. Cathodic protection of steel in concrete. BSI, London, UK.

BSI (2004a) BS EN 1337-4:2004. Structural bearings. Roller bearings. BSI, London, UK.

BSI (2004b) BS EN 1337-6:2004. Structural bearings. Rocker bearings. BSI, London, UK.

BSI (2004c) BS EN 1992-1-1:2004. Eurocode 2. Design of concrete structures. General rules and rules for buildings. BSI, London, UK.

BSI (2005) BS EN 1993-1-8:2005. Eurocode 3. Design of steel structures. Design of joints. BSI, London, UK.

BSI (2006a) BS EN 1993-1-5:2006. Eurocode 3. Design of steel structures. Plated structural elements. BSI, London, UK.

BSI (2006b) BS EN 1993-2:2006. Eurocode 3. Design of steel structures. Steel bridges. BSI, London, UK.

Concrete Society (1989) Cathodic protection of reinforced 
concrete. Concrete Society (Corrosion Engineering Association), Camberley, UK. Technical report no. 36. Hendy CR, Sandberg J and Shetty NK (2011) Recommendations for assessment Eurocodes for bridges. Proceedings of the ICE - Bridge Engineering 164(1): 3-14. http://dx.doi.org/10. 1680/bren.900030.

Highways Agency (1995) BD 44/95, The assessment of concrete highway bridges and structures. Highways Agency, London, UK.

Highways Agency (2010) BD 56/10, The assessment of steel highway bridges and structures. Highways Agency, London, UK.

NACE (National Association of Corrosion Engineers) (2000) Standard Recommended Practice - Cathodic Protection of Reinforcing Steel in Atmospherically Exposed Concrete Structures. NACE International, Houston, TX, USA. Smith DA and Hendy CR (2008) Strengthening of Irwell Valley Bridge, UK. Proceedings of the ICE - Bridge Engineering 161(1): 33-43. http://dx.doi.org/10.1680/bren.2008. 161.1.33.

\section{WHAT DO YOU THINK?}

To discuss this paper, please email up to 500 words to the editor at journals@ice.org.uk. Your contribution will be forwarded to the author(s) for a reply and, if considered appropriate by the editorial panel, will be published as discussion in a future issue of the journal.

Proceedings journals rely entirely on contributions sent in by civil engineering professionals, academics and students. Papers should be 2000-5000 words long (briefing papers should be 1000-2000 words long), with adequate illustrations and references. You can submit your paper online via www.icevirtuallibrary.com/content/journals, where you will also find detailed author guidelines. 